\title{
Exploration of Floral Volatile Organic Compounds in Six Typical Lycoris taxa by GC-MS
}

\author{
Tingting Shi ${ }^{1,+}$, Yuanzheng Yue ${ }^{1,+}$, Man Shi ${ }^{2}$, Min Chen ${ }^{1}$, Xiulian Yang ${ }^{1}$ and \\ Lianggui Wang 1,3,*
}

1 Key Laboratory of Landscape Architecture, Jiangsu Province, College of Landscape Architecture, Nanjing Forestry University, Nanjing 210037, China; tingtingshi@njfu.edu.cn (T.S.); yueyuanzheng@njfu.edu.cn (Y.Y.); xiaoximao2009@sina.com (M.C.); yangxl339@sina.com (X.Y.) College of Forestry, Nanjing Forestry University, Nanjing 210037, China; shiman1031@126.com

3 Co-Innovation Center for Sustainable Forestry in Southern China, Nanjing Forestry University, Nanjing 210037, China

* Correspondence: wlg@njfu.com.cn; Tel.: +86-1380-900-7625

+ These authors contributed equally to this work.

Received: 8 July 2019; Accepted: 13 October 2019; Published: 17 October 2019

\begin{abstract}
Lycoris, which is known as the 'Chinese tulip,' has diverse flower colors and shapes, and some species have a delicate fragrance. However, limited studies have reported the volatile organic compounds (VOCs) of Lycoris. In this study, headspace solid-phase microextraction combined with gas chromatography-mass spectrometry was used to analyze the floral VOCs of six typical Lycoris taxa. Thirty-two VOCs were identified, including terpenoids, alcohols, esters, aldehydes, ketones, and phenols. The aldehyde and terpenoid contents in Lycoris aurea were higher than in the other taxa, and the ester and alcohol contents in L. sprengeri were the highest compared to all taxa tested. Compared with other species and cultivars, L. longituba and L. longituba var. flava were the two most scented taxa and the VOCs were dominated by terpenoids and esters. L. radiate and L. chinensis were two unscented taxa and, accordingly, the VOC content was weak. A partial least squares discriminate analysis of the floral VOCs among the six Lycoris taxa showed that the six taxa could be successfully separated. Moreover, the VOCs of L. longituba and L. longituba var. flava clustered together. $\beta$-Ocimene was verified as the most important aroma compound, as determined via the calculation of the variable importance in projection values and significance analysis. $\beta$-Ocimene and its trans isomer, trans- $\beta$-ocimene, had a high relative content in $L$. longituba, L. longituba var. flava, $L$. aurea, and L. chinensis but were not detected in L. sprengeri and L. radiata. These results indicate that floral VOCs might be selected during the evolutional processes of Lycoris, and $\beta$-ocimene could be the most typical VOC among the different Lycoris taxa.
\end{abstract}

Keywords: Lycoris; tepal; aroma; GC-MS; volatile organic compounds

\section{Introduction}

Lycoris Herb. (Amaryllidaceae) contains approximately 20 species that are primarily located in Asia [1], with 15 species distributed in China [2]. Studies have been conducted on the medicinal properties [3-6], molecular cloning [7], karyotype [8], and evolutionary biology [9] of these Lycoris species. Due to the particular shapes and various colors of the tepals, Lycoris is an important ornamental flower in the summer [10].

Floral scents are secondary metabolites released by flowers and are mainly composed of many low molecular weight volatile compounds, including terpenes, benzenoid aromatics, and fatty acid derivatives [11]. Floral aroma is an important trait within ornamental plants and is also a critical factor 
in evolution because these olfactory signals (i.e., floral volatile organic compounds (VOCs)) attract pollinators [12,13]. For example, in Chiloglottis orchids, the presence of specific volatile 'chiloglottones' attracts specialist pollinators, which may lead to reproductive isolation and affect evolution [14]. In addition, the VOCs in flowers serve multiple biological functions, such as defense against pests, herbivores, and colonizing microorganisms $[15,16]$, which are generally correlated with the evolution of floral scents [17]. Recently, many Lycoris taxa with excellent and special fragrances were identified in our Lycoris germplasm resource nursery [18]. For example, the aromas of L. longituba and L. longituba var. flava have wintergreen and lily notes, while L. aurea has a citrus aroma. Some Lycoris species are represented by many particular scents; however, few scientific studies have been conducted on the different volatile compounds that Lycoris flowers produce and emit, or the variation of volatile compounds emitted from Lycoris species.

Headspace solid-phase microextraction (HS-SPME) can be used to extract components via the selective adsorption characteristics of the extracted fibers, and this method can be used to collect VOCs from flowers. For example, HS-SPME was used to collect the different categories of compounds released by different Freesia taxa [19]. Another study examined different solid-phase microextraction (SPME) conditions for achieving the optimum collection methods of floral volatiles from Echinacea [20]. Recently, partial least squares-discriminate analysis (PLS-DA) has been applied to identify VOCs and evaluate their quality in many plant species. In a previous study based on VOCs profiles, seven different cultivars of Polianthes tuberose could be distinguished from each other and four distinct clusters were obtained by PLS-DA [21]. Briefly, many different plant taxa could be distinguished by PLS-DA [22-24]. Moreover, PLS-DA could also reveal the core differential VOCs, such as in 42 different apple varieties [25]. Meanwhile, the variable importance in projection (VIP), one of the variable importance factors of PLS-DA, has been widely used in different fields and was previously shown to be effective for raw total ion GC-MS chromatogram data [26,27].

Six Lycoris taxa with different, yet common among the genus, flower colors and shapes were sampled in this study. HS-SPME-GC-MS and PLS-DA were used to analyze, quantify, and characterize the floral VOCs emitted from different Lycoris taxa. To the best of our knowledge, this is the first comparison of floral VOCs in different Lycoris taxa.

\section{Results}

\subsection{Identification of $V O C s$}

The floral VOCs of the six Lycoris taxa were analyzed by GC-MS, and the representative total ion chromatogram is shown in Figure 1. Thirty-two floral VOCs were identified, including terpenoids, alcohols, esters, aldehydes, ketones, and phenols (Table S1). The aroma profiles and total volatile content of the six taxa varied. For example, among the identified terpenoids, $\beta$-ocimene and its trans isomer, trans- $\beta$-ocimene, were not detected in L. sprengeri and L. radiata, but had a high relative content in L. longituba, L. longituba var. flava, L. aurea, and L. chinensis. Moreover, caryophyllene was only found in $L$. longituba, $\alpha$-farnesene was only found in $L$. aurea, and trans- $\beta$-farnesene was only detected in $L$. sprengeri (Table S1). Interestingly, no terpenoid was discovered in L. radiata (Table S1). 

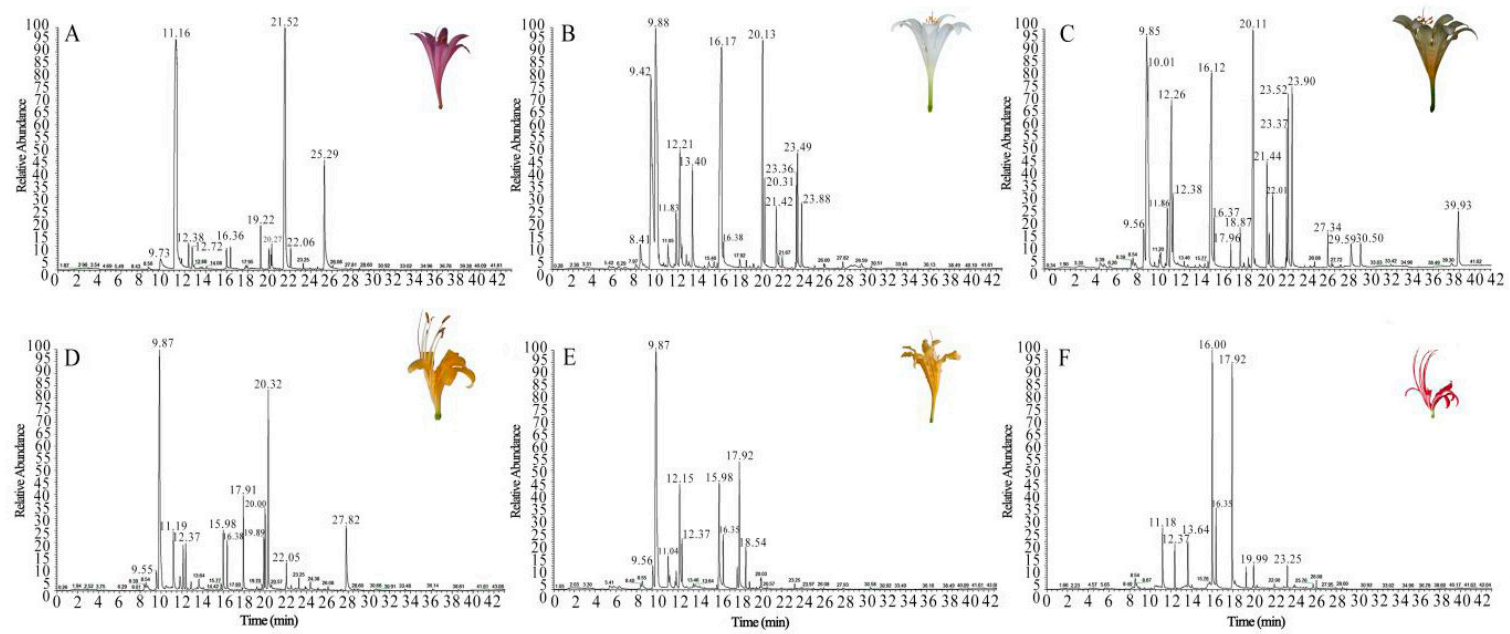

Figure 1. GC-MS total ion chromatograms of volatile organic compounds in six Lycoris taxa. (A) $L$. sprengeri; (B) L. longituba; (C) L. longituba var. flava; (D) L. aurea; (E) L. chinensis; (F) L. radiate.

Different floral VOCs were identified in the six Lycoris taxa. L. longituba had a relatively high content of terpenoids and esters, which were the main VOCs. Moreover, the relative content of esters was much larger than that of terpenoids (Figure 2). L. longituba var. flava contained similar floral VOCs as L. longituba, mainly consisting of terpenoids, esters, and a small amount of phenols. However, there were also differences in the VOC content between L. longituba var. flava and L. longituba. Specifically, the terpenoid and ester content were similar, and a small amount of alcohols and aldehydes were also detected, which made the aroma of L. longituba var. flava more complex in its sensory experience than L. longituba (Figure 2). In comparison, L. sprengeri mainly contained esters and alcohols, and the content of esters accounted for more than $88 \%$ of the total VOC content of L. sprengeri (Figure 2). In addition, the floral VOCs in L. aurea had the highest content of terpenoids, followed by aldehydes, as well as a small number of ketones. These compounds have a strong citrus aroma, a distinguishing characteristic that is easy to identify, which mainly defined the aroma of L. aurea (Figure 2). The VOC content in L. chinensis and L. radiata differed greatly from other Lycoris taxa. L. chinensis and L. radiata are essentially non-fragrant, with only a small amount of terpenoids, esters, and aldehydes detected in L. chinensis. Similarly, only a small number of aldehydes was detected in L. radiate (Figure 2).

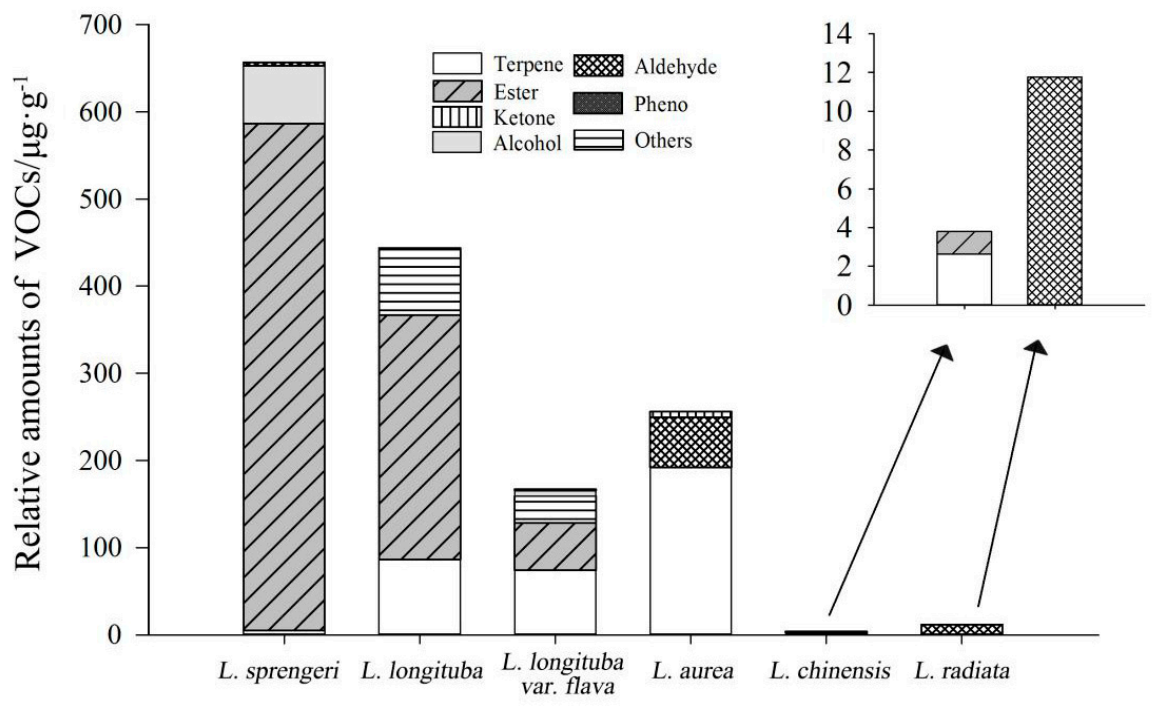

Figure 2. The content of various classes of aromatic compounds in six Lycoris taxa. Aromatic compounds mainly include terpenoids, alcohols, esters, aldehydes, ketones, and phenols. 


\subsection{Chemometric Analysis of VOCs}

PLS-DA, a supervised pattern recognition method, is commonly used to analyze VOCs and is often combined with hierarchical cluster analysis (HCA) to interpret the data obtained from GC-MS [28]. In this study, PLS-DA was carried out to better understand the characters of the VOCs of the six Lycoris taxa. In Figure 3a, it is shown that the first principle component ( $\mathrm{PC1}$, representing $31.5 \%$ ) and the second principle component (PC2, representing $19.2 \%$ ) of the total variation in the data could separate all six Lycoris taxa. PC1 could discriminate L. longituba and L. longituba var. flava from the other taxa and PC2 indicated differentiation among L. sprengeri and L. aurea and could also distinguish the scentless taxa (i.e., L. chinensis and L. radiata) from the other taxa (Figure 3a).

This model showed good stability and good predictability for the six different Lycoris taxa, and the loading plot displayed information distinguishing the taxa from each other (Figure 3b). The main contributors corresponding to the identity of L. longituba were caryophyllene, trans- $\beta$-ocimene, NA3, benzyl isovalerate, and isoamyl benzoate, which mainly corresponded to clusters 2-3 and 3 in Figure 3c. L. longituba var. flava was significantly associated with geranyl linallol, 9-octadecyne, and NA2, which mainly corresponded to cluster 2-2 in Figure 3c. The VOCs distributed in the higher positive value of PC2, such as $\beta$-ocimene, nonanal, $\beta$-ionone, (E)-2,7-dimethyl-3-octen-5-yne, decanal, and $\alpha$-farnesene, which corresponded to cluster 1 in Figure $3 c$, were correlated with L. aurea. In contrast, benzyl benzoate, methyl 2-ethylhexanoate, benzyl acetate, E-nerolidol, and trans- $\beta$-farnesene, which mainly corresponded to cluster 2-1 in Figure 3c, could distinguish L. sprengeri from the other taxa. The difference in L. chinensis and L. radiata was not clear by the loading plot, which may also be related to their lack of fragrance. Furthermore, the analysis of results showed that L. longituba and L. longituba var. flava as well as L. chinensis and $L$. radiate were respectively clustered together.

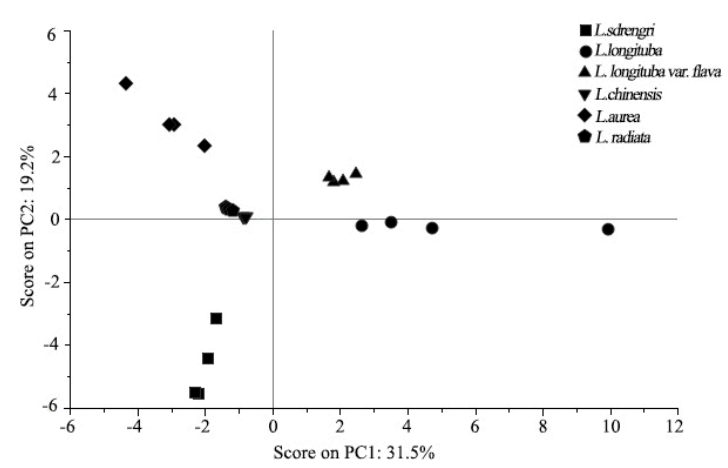

(a)

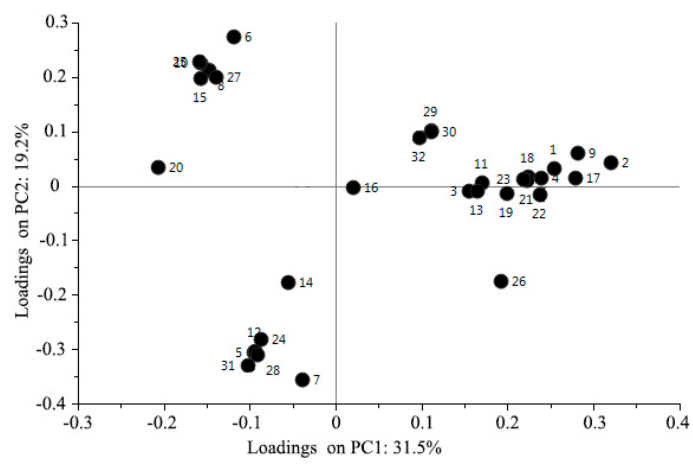

(b)

Figure 3. Cont. 


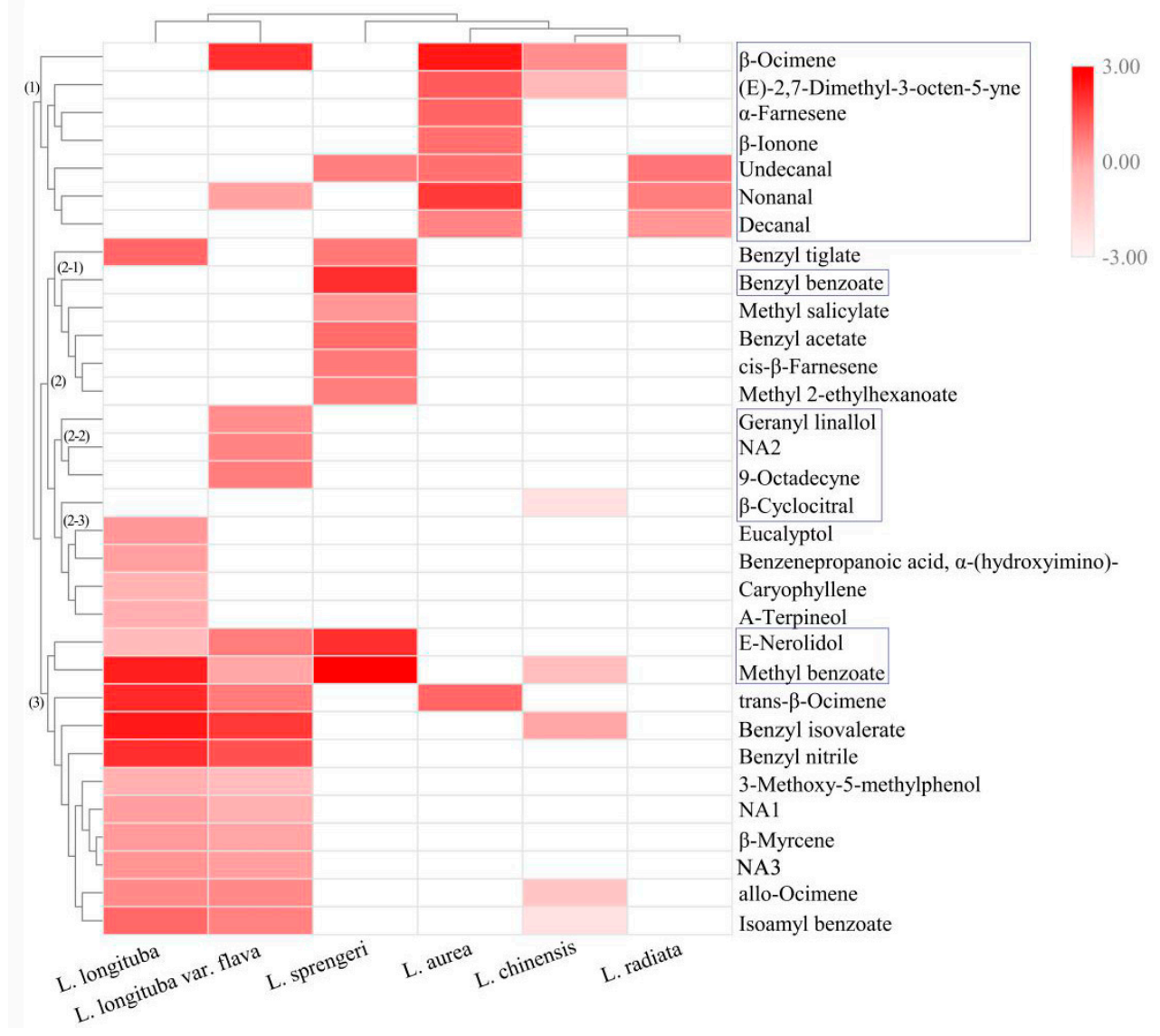

(c)

Figure 3. Chemometric analysis of volatile organic compounds (VOCs) in six Lycoris taxa detected by GC-MS. (a) Score plot and (b) loading plot of tepal GC-MS profiles of six Lycoris taxa using a partial least squares-discriminant analysis (PLS-DA). (c) Clustering of the 32 VOCs detected in six Lycoris taxa. VOCs coded in the loading plot were: (1) NA3; (2) $\beta$-myrcene; (3) eucalyptol; (4) trans- $\beta$-ocimene; (5) methyl 2-ethylhexanoate; (6) $\beta$-ocimene; (7) methyl benzoate; (8) nonanal; (9) allo-ocimene; (10) (E)-2,7-dimethyl-3-octen-5-yne; (11) benzyl nitrile; (12) benzyl acetate; (13) A-terpineol; (14) methyl salicylate; (15) decanal; (16) $\beta$-cyclocitral; (17) 3-methoxy-5-methylphenol; (18) NA1; (19) benzenepropanoic acid, $\alpha$-(hydroxyimino)-; (20) undecanal; (21) benzyl isovalerate; (22) caryophyllene; (23) isoamyl benzoate; (24) trans- $\beta$-farnesene; (25) $\beta$-ionone; (26) benzyl tiglate; (27) $\alpha$-farnesene; (28) E-nerolidol; (29) NA2; (30) 9-octadecyne; (31) benzyl benzoate; and (32) geranyl linallol. The compounds in black frames are the 14 key VOCs. White indicates low expression and red indicates high expression.

\subsection{Determination of Key VOCs}

The larger the VIP value, the more significant the difference in the variables. When the VIP value is greater than 1 , the corresponding variable can be defined as the key variable of the discriminant model [27]. In the PLS-DA model established in this study, there were 14 compounds with a VIP value greater than 1 -namely, $\beta$-ocimene, $\beta$-cyclocitral, 9-octadecyne, undecanal, $\beta$-ionone, geranyl linallol, (E)-2,7-dimethyl-3-octen-5-yne, methyl benzoate, $\alpha$-farnesene, nonanal, benzyl benzoate, decanal, E-nerolidol, and NA2 (Table 1). The above VOCs were identified as key differential aroma components among the six different Lycoris taxa. To improve the accuracy of the analysis, a Kruskal-Wallis test was applied to further analyze the VOCs with a VIP value greater than 1 . We found that the 14 VOCs were all statistically significantly different $(p<0.05)$ among the six different Lycoris taxa. Therefore, after combining the results of PLS-DA and the nonparametric test analysis, 14 key differential 
components in the six different Lycoris taxa were identified. In addition, the 14 key VOCs had a certain regularity in the distribution within the six Lycoris taxa (Figure 3c, in black frames). $\beta$-Ocimene, (E)-2,7-dimethyl-3-octen-5-yne, undecanal, decanal, nonanal, $\beta$-ionone, and $\alpha$-farnesene had the highest contents in L. aurea. These floral VOCs are mainly aldehydes and terpenoids, and the aromas of these compounds are generally citrus and floral notes. Methyl benzoate, E-nerolidol, and benzyl benzoate were higher in L. sprengeri, and these compounds typically have floral, fruity, and woody notes.

Table 1. Characteristics of the 14 key VOCs in the PLS-DA model.

\begin{tabular}{ccccc}
\hline NO. & Compounds & VIP $^{*}$ & $\boldsymbol{P}$ Value & Aroma Characteristics \\
\hline 1 & $\beta$-ocimene & 1.32 & 0.000 & citrus, floral, woody \\
2 & $\beta$-cyclocitral & 1.31 & 0.006 & saffron, rose, tobacco, fruity \\
3 & NA2 & 1.31 & 0.000 & - \\
4 & 9-octadecyne & 1.3 & 0.000 & - \\
5 & undecanal & 1.28 & 0.001 & soapy, floral, citrus \\
6 & $($ E)-2,7-dimethyl-3-octen-5-yne & 1.27 & 0.000 & - \\
7 & $\beta$-ionone & 1.15 & 0.000 & woody, berry, floral, fruity \\
8 & geranyl linallol & 1.15 & 0.000 & rose \\
9 & methyl benzoate & 1.12 & 0.001 & wintergreen, cananga \\
10 & $\alpha$-farnesene & 1.12 & 0.000 & citrus, lavender, neroli \\
11 & nonanal & 1.06 & 0.000 & rose, orris, citrus \\
12 & benzyl benzoate & 1.04 & 0.000 & balsam, fruity \\
13 & decanal & 1.01 & 0.001 & citrus, floral \\
14 & E-nerolidol & 1 & 0.000 & floral, citrus, woody \\
\hline
\end{tabular}

*VIP: variable importance in projection.

L. longituba contained the highest content of methyl benzoate, which typically has wintergreen and cananga notes. This is consistent with the sensory evaluation results of L. longituba, indicating that this compound may play an important role in the formation of the aroma of L. longituba. 9-Octadecyne and geranyl linallol were only detected in L. longituba var. flava. L. longituba var. flava also contained $\beta$-ocimene and E-nerolidol; these compounds have a floral, citrus, and woody aroma. Compared to the other taxa, L. chinensis and L. radiata were essentially unscented, with the corresponding lack of aroma components. It is hypothesized that the different VOC contents in different Lycoris taxa have an important influence on the aroma of the corresponding Lycoris taxa.

\section{Discussion}

Floral scent is a desirable feature for ornamental plants; previous studies have determined the scent compounds and patterns of release for several ornamental species such as Lilium [29], Jasminum sambac [30], and Osmanthus fragrans [31]. There are many factors affecting the type and content of floral fragrance, but it mainly depends on the genetic characteristics of the taxa. A study on the floral scents in eight lily taxa demonstrated that the floral VOCs emitted from scented and non-scented flowers were qualitatively and quantitatively distinct [32]. Moreover, the floral VOCs released by different Narcissus pseudonarcissus varieties also had qualitative and quantitative differences [33]. Recently, the regulation mechanism of aroma biosynthesis has been well clarified by genomic, transcriptomic, and proteomic investigations, such as in O. fragrans [31], Lilium [34], and Chimonanthus praecox [35]. Although the fragrance of Lycoris is valued, previous studies have mainly focused on its medicinal value and properties, especially of its bulb [36-38]. This study is the first to compare the differences in floral VOCs between different Lycoris taxa, including scented and unscented taxa (Table 2). Our results confirmed that the constituents and relative composition of floral VOCs were different by comparing six Lycoris taxa (Figure 3c). The results may not only provide insight into the floral metabolic networking in Lycoris, but also provide valuable information for the ornamental breeding of Lycoris for its scent. 
Table 2. Flower characteristics of six typical Lycoris taxa from a natural population.

\begin{tabular}{|c|c|c|c|c|c|c|}
\hline Parameters & L. sprengeri & L. longituba & $\begin{array}{l}\text { L. longituba var. } \\
\text { flava }\end{array}$ & L. aurea & L. chinensis & L. radiate \\
\hline Flower & & & & & & \\
\hline Color & Purple & White & Light yellow & Yellow & Yellow & Red \\
\hline Height (cm) & $13.56 \pm 0.63^{c}$ & $16.02 \pm 0.87^{\mathrm{d}}$ & $16.24 \pm 0.86^{\mathrm{de}}$ & $10.88 \pm 1.07^{\mathrm{b}}$ & $17.78 \pm 1.14^{\mathrm{e}}$ & $5.55 \pm 0.60^{\mathrm{a}}$ \\
\hline Breadth $(\mathrm{cm})$ & $10.29 \pm 0.76^{\mathrm{b}}$ & $13.59 \pm 0.81^{\mathrm{cd}}$ & $14.77 \pm 0.96^{\mathrm{d}}$ & $10.31 \pm 0.54^{b}$ & $13.01 \pm 0.54^{c}$ & $8.48 \pm 0.59^{\mathrm{a}}$ \\
\hline Aroma level & Scented & Scented & Scented & Scented & Non-scented & Non-scented \\
\hline
\end{tabular}

Note: All values are the mean \pm s.d. of four replicates. Values having same letters do not vary significantly at $p<0.05$.

Floral scent is determined by a broad range of compounds and their complex mixture. The majority of floral VOCs are terpenoids or benzenoids, but alcohols, ketones, fatty acids, and esters may also be present. It has been demonstrated that different floral compounds could attract different pollinators. In addition, the circadian emission patterns of plant VOCs are associated with pollinators. For example, Narcissus flowers were found to produce fewer VOCs at night than during the day [39], whereas Nicotiana show the opposite trend due to pollinator-mediated selection [40]. Differences in floral VOC variation are influenced by special pollinators and shared evolutionary history. In this study, the floral VOCs of six Lycoris taxa had significant differences, and they could be effectively distinguished by PLS-DA (Figure 3a). Among the six Lycoris taxa, L. longituba and L. longituba var. flava clustered close together, which is logical because these taxa are closely related based on karyotype information and phylogenetic relationships [41,42]. Interestingly, in the other four Lycoris taxa, L. chinensis and L. radiata clustered close together, whereas L. sprengeri and L. aurea could be discriminated from one another (Figure 3a). However, a phylogenetic study showed that L. chinensis and L. aurea were clustered in the same group with L. longituba and L. longituba var. flava, and L. sprengeri and L. radiata were clustered in another group [43], which is inconsistent with the PLS-DA and HCA results (Figure 3). This may be because, in addition to scent, other floral traits such as color can also affect pollinator behavior, thereby affecting reproductive isolation, leading to evolution. Studies conducted on Petunia axillaris and P. exserta, two sister species, showed that P. axillaris is white and scented, whereas the red flowers of P. exserta lack scent [44]. Similarly, in the six Lycoris taxa, the flowers of L. longituba are white and heavily scented, while L. radiata is bright red and unscented. Moreover, the flower size, flower shape, and pollen of the six Lycoris taxa are also different from each other (Table 2). Differences in floral traits, such as petal color, scent, or shape, can all lead to different interactions with pollinators. Lycoris flowers are diverse in color and shape, which may also affect the evolution of Lycoris.

Some evidence showed that $\beta$-ocimene may function as a general pollinator attractant [45]. The phenomenon of emitting $\beta$-ocimene from flowers is widely distributed and the trait has been gained and lost several times across the phylogeny of flowering plants [46]. $\beta$-Ocimene was verified as the most important aroma compound of the six Lycoris taxa. Furthermore, a comparison of the floral aroma during the tepal development of L. longituba indicated that trans- $\beta$-ocimene was also the most important aroma compound [18]. $\beta$-Ocimene is one of the most common floral VOCs [46], and it is also a major component of the floral aroma of many species $[35,47,48]$. This study detected $\beta$-ocimene and its trans isomer, trans- $\beta$-ocimene, which had a high relative content in L. longituba, L. longituba var. flava, L. chinensis, and L. aurea; these compounds were not detected in L. sprengeri and L. radiate (Table S1). This finding is consistent with the phylogenetic analysis, wherein L. longituba, L. longituba var. flava, $L$. chinensis, and L. aurea were in one clade, while L. sprengeri and L. radiate formed another clade [43]. This suggested that $\beta$-ocimene may be related to the evolutionary relationships among Lycoris species. 
Some plant VOCs that have antibacterial and antifungal properties can develop inhibitory effects against microbial pathogens $[49,50]$. In a previous study, the VOCs of conifers were found to have an inhibitory effect on the growth of airborne microorganisms [51]. By analyzing the effects of the VOCs of five conifer species that inhibit microbes, it was found that limonene, $\beta$-pinene, pelargon aldehyde, decanal, and benzaldehyde could significantly inhibit bacterial growth. Terpenoids have pronounced roles in antimicrobial activities [52]. Our study detected many terpenoids in the six Lycoris taxa, among which the key differential compound $\beta$-ocimene is also a monoterpene compound, suggesting that the flowers of Lycoris might have some ecological values. Moreover, some common plant VOCs are also predominant components of essential oils, such as benzaldehyde, linalool, limonene and $\beta$-ocimene. To our best knowledge, plant essential oils have a significant impact on human health $[53,54]$. At present, rose essential oil and lavender essential oil have been extensively used in the perfumery, aromatherapy, and medical industries. The differences in aromatic characteristics of essential oils may result in different effects. For example, a citrus aroma has a calming effect [55]. The aroma characteristics of our key floral VOCs, i.e., $\beta$-ocimene, $\beta$-cyclocitral, undecanal, and methyl benzoate, are generally citrus and floral, which can affect human mood and health. In summary, this study could provide a theoretical basis for the utilization of floral scent components in Lycoris and expand the application field of Lycoris.

\section{Materials and Methods}

\subsection{Materials and Chemicals}

Six typical Lycoris taxa, including L. longituba, L. longituba var. flava, L. radiate, L. aurea, and $L$. chinensis (Table 2), were selected from the Lycoris germplasm resource nursery of Nanjing Forestry University in Nanjing, China. Fresh tepals of each Lycoris taxa were collected randomly, and each sample was analyzed in quadruplicate.

Analytical grade ethyl caprate and methyl alcohol were purchased from Maclean Biotechnology Co., Ltd. (Shanghai, China). The mixture of n-alkane standards (C7-C40) was obtained from Sigma-Aldrich (St. Louis, MO, USA).

\subsection{Sample Pretreatment}

Tepals $(0.3 \mathrm{~g}$ ) were placed in a $20 \mathrm{~mL}$ solid-phase microextraction vial (Supelco Inc, Bellefonte, PA, USA). Then, $1 \mu \mathrm{L}$ of $3000 \times$ diluted ethyl caprate was added to the sample as an internal standard for GC-MS analysis and the vial was capped with a polytetrafluoroethylene (PTFE)-silicon stopper.

The sample vial was maintained at $25^{\circ} \mathrm{C}$ for $30 \mathrm{~min}$ to equilibrate on a magnetic platform (PC-400, Supelco Inc., Bellefonte, PA, USA). Afterwards, the VOCs were extracted by solid-phase microextraction (SPME) fiber ( $65 \mu \mathrm{m}$ PDMS/DVB, Supelco Inc.) for $60 \mathrm{~min}$ at $50{ }^{\circ} \mathrm{C}$. Then, the fiber was immediately desorbed into the GC system.

\subsection{GC-MS Analysis}

The GC-MS analysis was carried out using a TSQ80000EVO gas chromatograph-mass spectrometer (Thermo Fisher Scientific, PA, USA). Floral VOCs were desorbed at $250{ }^{\circ} \mathrm{C}$ for $2 \mathrm{~min}$ using the splitless mode and separated on a TG-5MS column $(30 \mathrm{~m} \times 0.25 \mathrm{~mm} \times 0.25 \mu \mathrm{m})$ with a carrier gas (helium) at a linear velocity of $1.2 \mathrm{~mL} / \mathrm{min}$. The temperature was programmed at $40^{\circ} \mathrm{C}$ for $1 \mathrm{~min}$, increased to $280{ }^{\circ} \mathrm{C}$ gaining $6{ }^{\circ} \mathrm{C} / \mathrm{min}$, followed by maintaining the temperature of the transfer line at $280{ }^{\circ} \mathrm{C}$. The electronic ionization mode on the mass spectrometer was set at $70 \mathrm{eV}$ with a mass scan range of 40 to 550 atomic mass units (amu).

\subsection{Identification and Quantification}

The retention indices (RIs) were calculated by the retention time (RT) of n-alkane standards (C7-C40) under the same conditions. Floral VOCs were identified by the RIs and mass spectra 
compared with the reference standards in the NIST08 library. When reference standards were not available, the identifications were performed by comparing their mass spectra with those in the NIST08 library and RIs reported in the literature. The VOC content was calculated by normalizing the peak areas.

\subsection{Statistical Analysis}

One-way analysis of variance (ANOVA) and the Kruskal-Wallis test were conducted by SPSS 20.0 software for Windows (Microsoft, NY, USA). Partial least squares-discriminate analysis (PLS-DA) was performed by SIMCA 13.0 software (Umetrics, Umeå, Sweden), and hierarchical cluster analysis (HCA) was conducted by TBtools software (CJ Chen, Guangzhou, China) with the mean value of the relative content of VOCs. Aroma characteristics were obtained from the "The Good Scents" company network database (www.thegoodscentscompany.com).

\section{Conclusions}

Lycoris is a perennial bulb flower with ornamental and medical values. This study is the first to compare the floral VOCs among six Lycoris taxa. We identified 32 floral VOCs and revealed the difference in VOC compounds and the relative composition of the VOCs within the six Lycoris taxa. Different Lycoris taxa released different floral VOCs. The PLS-DA analysis could effectively distinguish the six Lycoris taxa based on their floral VOCs, and L. longituba and L. longituba var. flava were clustered together. In addition, $\beta$-ocimene was verified as the most important aroma compound. The high relative content of $\beta$-ocimene and its trans isomer, trans- $\beta$-ocimene, were detected in $L$. longituba, $L$. longituba var. flava, L. aurea, and L. chinensis, but not in L. sprengeri and L. radiata, which supports the phylogenetic relationships of the six Lycoris taxa. Our data suggested that the floral VOCs, especially $\beta$-ocimene, may be related to the evolution of Lycoris. Our results not only provide valuable information for the ornamental breeding of Lycoris, but also help to further the understanding of the adaptive evolution of the floral VOCs of Lycoris.

Supplementary Materials: The following are available online at http://www.mdpi.com/2223-7747/8/10/422/s1, Table S1: The floral volatile organic compounds of different Lycoris taxa.

Author Contributions: Conceptualization, T.S. and Y.Y.; methodology, T.S. and M.S.; software, T.S. and Y.Y.; validation, Y.Y. and T.S.; formal analysis, M.C.; data curation, T.S.; writing-original draft preparation, T.S.; writing-review and editing, Y.Y.; visualization, X.Y.; supervision, L.W.; project administration, L.W.; funding acquisition, L.W.

Funding: This research was funded by the Shanghai Agriculture Applied Technology Development Program (Grant No. G20160503), the National Natural Science Foundation of China (Grant No. 31601785 and 31870695), and the Priority Academic Program Development of Jiangsu Higher Education Institutions (PAPD).

Conflicts of Interest: The authors declare no conflict of interest.

\section{References}

1. Ang, S.; Liu, X.-M.; Huang, X.-J.; Zhang, D.-M.; Zhang, W.; Wang, L.; Ye, W.-C. Four New Amaryllidaceae Alkaloids from Lycoris radiata and Their Cytotoxicity. Planta Med. 2015, 81, 1712-1718. [CrossRef]

2. Tsi, Z.H.; Meerow, A.W. Amaryllidaceae. In Flora of China; Wu, C.Y., Raven, P.H., Eds.; Beijing Science Press \& Missouri Botanical Garden Press: Beijing, China, 2000; Volume 24, p. 264.

3. Takos, A.M.; Rook, F. Towards a Molecular Understanding of the Biosynthesis of Amaryllidaceae Alkaloids in Support of Their Expanding Medical Use. Int. J. Mol. Sci. 2013, 14, 11713-11741. [CrossRef]

4. Yan, H.; Xie, N.; Zhong, C.; Su, A.; Hui, X.; Zhang, X.; Jin, Z.; Li, Z.; Feng, J.; He, J. Aphicidal activities of Amaryllidaceae alkaloids from bulbs of Lycoris radiata against Aphis citricola. Ind. Crop. Prod. 2018, 123, 372-378. [CrossRef]

5. Li, A.; Du, Z.; Liao, M.; Feng, Y.; Ruan, H.; Jiang, H. Discovery and characterisation of lycorine-type alkaloids in Lycoris spp. (Amaryllidaceae) using UHPLC-QTOF-MS. Phytochem. Anal. 2019, 30, 268-277. [CrossRef] 
6. Shen, C.-Y.; Xu, X.-L.; Yang, L.-J.; Jiang, J.-G. Identification of narciclasine from Lycoris radiata (L'Her.) Herb. and its inhibitory effect on LPS-induced inflammatory responses in macrophages. Food Chem. Toxicol. 2019, 125, 605-613. [CrossRef]

7. Sun, B.; Wang, P.; Wang, R.; Li, Y.; Xu, S. Molecular Cloning and Characterization of a meta/para-O-Methyltransferase from Lycoris aurea. Int. J. Mol. Sci. 2018, 19, 1911. [CrossRef]

8. Meng, W.; Zhang, D.; Qin, H.; Wang, L.; Zheng, L.; Xia, Q.; Liu, K. Hybrid Origin of Lycoris shaanxiensis Revealed by Karyotype Survey. Cytologia 2018, 83, 133-136. [CrossRef]

9. Chen, I.-J.; Shii, C.-T.; Chang, T.-L.; Hwu, K.-K. Development of 17 novel microsatellite markers for Lycoris aurea and L. radiata (Amaryllidaceae) using next-generation sequencing. Appl. Plant Sci. 2018, 6, e01198. [CrossRef]

10. He, Q.; Shen, Y.; Wang, M.; Huang, M.; Yang, R.; Zhu, S.; Wang, L.; Xu, Y.; Wu, R. Natural Variation in Petal Color in Lycoris longituba Revealed by Anthocyanin Components. PLoS ONE 2011, 6, e22098. [CrossRef] [PubMed]

11. Dudareva, N.; Klempien, A.; Muhlemann, J.K.; Kaplan, I. Biosynthesis, function and metabolic engineering of plant volatile organic compounds. New Phytol. 2013, 198, 16-32. [CrossRef] [PubMed]

12. Borghi, M.; Fernie, A.R.; Schiestl, F.P.; Bouwmeester, H.J. The Sexual Advantage of Looking, Smelling, and Tasting Good: The Metabolic Network that Produces Signals for Pollinators. Trends Plant Sci. 2017, 22, 338-350. [CrossRef] [PubMed]

13. Schiestl, F.P. Ecology and evolution of floral volatile-mediated information transfer in plants. New Phytol. 2015, 206, 571-577. [CrossRef] [PubMed]

14. Peakall, R.; Whitehead, M.R. Floral odour chemistry defines species boundaries and underpins strong reproductive isolation in sexually deceptive orchids. Ann. Bot. 2013, 113, 341-355. [CrossRef] [PubMed]

15. Holopainen, J.K.; Gershenzon, J. Multiple stress factors and the emission of plant VOCs. Trends Plant Sci. 2010, 15, 176-184. [CrossRef] [PubMed]

16. Ortega, R.A.; Mahnert, A.; Müller, H.; Berg, C. The plant is crucial: Specific composition and function of the phyllosphere microbiome of indoor ornamentals. FEMS Microbiol. Ecol. 2016, 92, 1-12. [CrossRef] [PubMed]

17. Schiestl, F.P. The evolution of floral scent and insect chemical communication. Ecol. Lett. 2010, 13, 643-656. [CrossRef] [PubMed]

18. Yue, Y.; Liu, J.; Shi, T.; Chen, M.; Li, Y.; Du, J.; Jiang, H.; Yang, X.; Hu, H.; Wang, L. Integrating Transcriptomic and GC-MS Metabolomic Analysis to Characterize Color and Aroma Formation during Tepal Development in Lycoris longituba. Plants 2019, 8, 53. [CrossRef] [PubMed]

19. Gao, F.; Liu, B.; Li, M.; Gao, X.; Fang, Q.; Liu, C.; Ding, H.; Wang, L.; Gao, X. Identification and characterization of terpene synthase genes accounting for volatile terpene emissions in flowers of Freesia x hybrida. J. Exp. Bot. 2018, 69, 4249-4265. [CrossRef]

20. Kaya, M.; Merdivan, M.; Tashakkori, P.; Erdem, P.; Anderson, J.L. Analysis of Echinacea flower volatile constituents by HS-SPME-GC/MS using laboratory-prepared and commercial SPME fibers. J. Essent. Oil Res. 2019, 31, 91-98. [CrossRef]

21. Kutty, N.N.; Mitra, A. Profiling of volatile and non-volatile metabolites in Polianthes tuberosa L. flowers reveals intraspecific variation among cultivars. Phytochemistry 2019, 162, 10-20. [CrossRef]

22. Zhu, Y.; Shao, C.-Y.; Lv, H.-P.; Zhang, Y.; Dai, W.-D.; Guo, L.; Tan, J.-F.; Peng, Q.-H.; Lin, Z. Enantiomeric and quantitative analysis of volatile terpenoids in different teas (Camellia sinensis). J. Chromatogr. A 2017, 1490, 177-190. [CrossRef] [PubMed]

23. Zhang, L.; Zeng, Z.; Zhao, C.; Kong, H.; Lü, X.; Xu, G. A comparative study of volatile components in green, oolong and black teas by using comprehensive two-dimensional gas chromatography-time-of-flight mass spectrometry and multivariate data analysis. J. Chromatogr. A 2013, 1313, 245-252. [CrossRef] [PubMed]

24. Cheng, Z.; Liu, X.; Wang, S.; Zhang, X.; Ma, L. Classification of Different Dried Vine Fruit Varieties in China by HS-SPME-GC-MS Combined with Chemometrics. Food Anal. Methods 2017, 10, 2856-2867. [CrossRef]

25. Giannetti, V.; Mariani, M.B.; Mannino, P.; Marini, F. Volatile fraction analysis by HS-SPME/GC-MS and chemometric modeling for traceability of apples cultivated in the Northeast Italy. Food Control. 2017, 78, 215-221. [CrossRef]

26. Farres, M.; Platikanov, S.; Tsakovski, S.; Tauler, R. Comparison of the variable importance in projection (VIP) and of the selectivity ratio (SR) methods for variable selection and interpretation. J. Chemom. 2015, 29, 528-536. [CrossRef] 
27. Wold, S.; Sjöström, M.; Eriksson, L. PLS-regression: A basic tool of chemometrics. Chemometr. Intell. Lab. Syst. 2001, 58, 109-130. [CrossRef]

28. Lubes, G.; Goodarzi, M. Analysis of Volatile Compounds by Advanced Analytical Techniques and Multivariate Chemometrics. Chem. Rev. 2017, 117, 6399-6422. [CrossRef]

29. Kong, Y.; Sun, M.; Pan, H.; Zhang, Q.; Ai, C.; Wang, Y. Floral scent composition of Lilium sulphureum. Chem. Nat. Compd. 2013, 49, 362-364. [CrossRef]

30. Bera, P.; Mukherjee, C.; Mitra, A. Enzymatic production and emission of floral scent volatiles in Jasminum sambac. Plant Sci. 2017, 256, 25-38. [CrossRef]

31. Yang, X.; Yue, Y.; Li, H.; Ding, W.; Chen, G.; Shi, T.; Chen, J.; Park, M.S.; Chen, F.; Wang, L. The chromosome-level quality genome provides insights into the evolution of the biosynthesis genes for aroma compounds of Osmanthus fragrans. Hortic. Res. 2018, 5, 72. [CrossRef]

32. Kong, Y.; Sun, M.; Pan, H.-T.; Zhang, Q.-X. Composition and Emission Rhythm of Floral Scent Volatiles from Eight Lily Cut Flowers. J. Am. Soc. Hortic. Sci. 2012, 137, 376-382. [CrossRef]

33. Li, X.; Tang, D.; Shi, Y. Volatile compounds in perianth and corona of Narcissus Pseudonarcissus cultivars. Nat. Prod. Res. 2019, 33, 2281-2284. [CrossRef] [PubMed]

34. Hu, Z.; Tang, B.; Wu, Q.; Zheng, J.; Leng, P.; Zhang, K. Transcriptome Sequencing Analysis Reveals a Difference in Monoterpene Biosynthesis between Scented Lilium 'Siberia' and Unscented Lilium 'Novano'. Front. Plant Sci. 2017, 8, 8. [CrossRef] [PubMed]

35. Tian, J.P.; Ma, Z.Y.; Zhao, K.G.; Zhang, J.; Xiang, L.; Chen, L.Q. Transcriptomic and proteomic approaches to explore the differences in monoterpene and benzenoid biosynthesis between scented and unscented genotypes of wintersweet. Physiol. Plant. 2019, 166, 478-493. [CrossRef]

36. Chun, J.-H.; Jang, I.H.; Arasu, M.V.; Al-Dhabi, N.A.; Duraipandiyan, V.; Lee, D.-H.; Lee, S.; Kim, S.-J. Isolation and identification of alkaloids and anthocyanins from flower and bulb of Lycoris radiata using HPLC and LC-ESI-MS. J. Agric. Chem. Environ. 2013, 2, 22-26. [CrossRef]

37. Tian, Y.; Zhang, C.; Guo, M. Comparative Analysis of Amaryllidaceae Alkaloids from Three Lycoris Species. Molecules 2015, 20, 21854-21869. [CrossRef]

38. Zhang, F.; Zhang, Y.-Y.; Thakur, K.; Zhang, J.-G.; Wei, Z.-J. Structural and physicochemical characteristics of lycoris starch treated with different physical methods. Food Chem. 2019, 275, 8-14. [CrossRef]

39. Ruíz-Ramón, F.; Águila, D.J.; Egea-Cortines, M.; Weiss, J. Optimization of fragrance extraction: Daytime and flower age affect scent emission in simple and double narcissi. Ind. Crop. Prod. 2014, 52, 671-678. [CrossRef]

40. Raguso, R.A.; Levin, R.A.; Foose, S.E.; Holmberg, M.W.; McDade, L.A. Fragrance chemistry, nocturnal rhythms and pollination "syndromes" in Nicotiana. Phytochemistry 2003, 63, 265-284. [CrossRef]

41. Shi, S.; Qiu, Y.; Wu, L.; Fu, C. Interspecific relationships of Lycoris (Amaryllidaceae) inferred from inter-simple sequence repeat data. Sci. Hortic. 2006, 110, 285-291. [CrossRef]

42. Shi, S.; Qiu, Y.; Li, E.; Wu, L.; Fu, C. Phylogenetic Relationships and Possible Hybrid Origin of Lycoris Species (Amaryllidaceae) Revealed by ITS Sequences. Biochem. Genet. 2006, 44, 198-208. [CrossRef] [PubMed]

43. Shi, S.; Sun, Y.; Wei, L.; Lei, X.; Cameron, K.M.; Fu, C. Plastid DNA sequence data help to clarify phylogenetic relationships and reticulate evolution in Lycoris (Amaryllidaceae). Bot. J. Linn. Soc. 2014, 176, 115-126.

44. Klahre, U.; Gurba, A.; Hermann, K.; Saxenhofer, M.; Bossolini, E.; Guerin, P.M.; Kuhlemeier, C. Pollinator Choice in Petunia Depends on Two Major Genetic Loci for Floral Scent Production. Curr. Boil. 2011, 21, 730-739. [CrossRef] [PubMed]

45. Farré-Armengol, G.; Filella, I.; Llusià, J.; Peñuelas, J. Floral volatile organic compounds: Between attraction and deterrence of visitors under global change. Perspect. Plant Ecol. Evol. Syst. 2013, 15, 56-67. [CrossRef]

46. Farré-Armengol, G.; Filella, I.; Llusià, J.; Peñuelas, J. $\beta$-Ocimene, a Key Floral and Foliar Volatile Involved in Multiple Interactions between Plants and Other Organisms. Molecules 2017, 22, 1148. [CrossRef]

47. Zeng, X.; Liu, C.; Zheng, R.; Cai, X.; Luo, J.; Zou, J.; Wang, C. Emission and Accumulation of Monoterpene and the Key Terpene Synthase (TPS) Associated with Monoterpene Biosynthesis in Osmanthus fragrans Lour. Front. Plant Sci. 2016, 6, 2739. [CrossRef]

48. Chamorro, E.R.; Ballerini, G.; Sequeira, A.F.; Velasco, G.A.; Zalazar, M.F. Chemical composition of essential oil from Tagetes minuta L. leaves and flowers. J. Argent. Chem. Soc. 2008, 96, 80-86.

49. Junker, R.R.; Tholl, D. Volatile Organic Compound Mediated Interactions at the Plant-Microbe Interface. J. Chem. Ecol. 2013, 39, 810-825. [CrossRef] 
50. Huang, M.; Sanchez-Moreiras, A.M.; Abel, C.; Sohrabi, R.; Lee, S.; Gershenzon, J.; Tholl, D. The major volatile organic compound emitted from Arabidopsis thaliana flowers, the sesquiterpene (E)- $\beta$-caryophyllene, is a defense against a bacterial pathogen. New Phytol. 2012, 193, 997-1008. [CrossRef]

51. Gao, Y.; Jin, Y.-J.; Li, H.-D.; Chen, H.-J. Volatile Organic Compounds and Their Roles in Bacteriostasis in Five Conifer Species. J. Integr. Plant Boil. 2005, 47, 499-507. [CrossRef]

52. Pichersky, E.; Raguso, R.A. Why do plants produce so many terpenoid compounds? New Phytol. 2018, 220, 692-702. [CrossRef] [PubMed]

53. Goepfert, M.; Liebl, P.; Herth, N.; Ciarlo, G.; Buentzel, J.; Huebner, J. Aroma oil therapy in palliative care: A pilot study with physiological parameters in conscious as well as unconscious patients. J. Cancer Res. Clin. Oncol. 2017, 143, 2123-2129. [CrossRef] [PubMed]

54. Jin, L.; Haviland-Jones, J.; Simon, J.E.; Tepper, B.J. Influence of aroma intensity and nasal pungency on the 'mood signature' of common aroma compounds in a mixed ethnic population. Food Qual. Prefer. 2018, 65, 164-174. [CrossRef]

55. Haehner, A.; Maass, H.; Croy, I.; Hummel, T. Influence of room fragrance on attention, anxiety and mood. Flavour Fragr. J. 2017, 32, 24-28. [CrossRef]

(C) 2019 by the authors. Licensee MDPI, Basel, Switzerland. This article is an open access article distributed under the terms and conditions of the Creative Commons Attribution (CC BY) license (http://creativecommons.org/licenses/by/4.0/). 